\title{
Digital Marketing Sebagai Strategi Pemasaran UMKM Makaroni Bajak Laut Kabupaten Temanggung
}

\author{
*Dimas Sasongko, Intan Rahma Putri, Vivi Nur Alfiani, Sasqia Dyah Qiranti, Riski Sinta \\ Sari, Pramania Elka Allafa \\ Fakultas Teknik Universitas Muhammadiyah Magelang \\ *E-mail : dimassasongko@ummgl.ac.id \\ DOI: https://doi.org/10.21107/pangabdhi.v6i2.7809 \\ Naskah diterima 6 Juli 2020, Revisi 1 Agustus 2020, Terbit 29 Oktober 2020
}

\begin{abstract}
Abstrak
Pesatnya perkembangan teknologi dunia digital dan internet tentu juga berimbas pada dunia pemasaran. digital marketing ini lebih prospektif karena memungkinkan para calon pelanggan memperoleh segala macam informasi mengenai produk dan bertransaksi melalui internet. Penjualan Makaroni Bajak Laut selama ini mengharuskan konsumen yang ingin memesan atau membeli produk untuk datang langsung ke lokasi atau memesan lewat WhatsApp untuk melihat produk yang akan dibeli.Tujuan kegiatan ini adalah memeberikan pelatihan dan pendampingan kepada UMKM Makaroni Bajak Laut tentang implementasi Digital Marketing sebagai strategi dalam memasarkan produk. Tahap pelatihan dan pendampingan terdiri dari beberapa kegiatan yaitu: (1) Pengenalan packaging dan branding, (2) Dokumentasi produk, (3) Pengenalan sosial media, (4) Pengenalan marketplace, (5) Menerima pesanan dan mengirim barang. Hasil dari Pengabdian Kepada Masyarakat adalah UMKM Makaroni Bajak Laut memiliki sosial media dan marketplace sebagai alat untuk melakukan promosi produk dan pemilik UMKM Makaroni Bajak Laut memiliki pemahaman tentang Digital Marketing serta mampu mengelola sosial media dan marketplace yang dimiliki.
\end{abstract}

Kata Kunci: digital marketing, UMKM, media sosial, marketplace

\begin{abstract}
The rapid development of technology in the digital world and the internet certainly also affected the world of marketing. Digital marketing is more prospective because it allows customers to get all information about products and transact through the internet. The sale of Makaroni Bajak Laut requires customers who want to order or buy products to come directly to the location or order via WhatsApp to see the products to be purchased. product. The training and assistance phase consists of several activities, namely: (1) Introduction to packaging and branding, (2) Product documentation, (3) Introduction to social media, (4) Market introduction, (5) Receiving orders and shipping goods. As a result of Community Service, the Makaroni Bajak Laut MSME has social media and marketplace as a tool for product promotion and the Makaroni Bajak Laut MSME owner has knowledge of Digital Marketing and provides supportive social media and marketplace.
\end{abstract}

Key Words: digital marketing, MSME, social media, marketplace

\section{PENDAHULUAN}

Koperasi dan UMKM merupakan jenis usaha yang memiliki peran penting dalam peningkatan PDB (Pendapatan Domestik Bruto) satu negara khususnya di Indonesia dengan menghadapi Era Industri 4.0 (Amri, 2020). Usaha Mikro Kecil dan Menengah (UMKM) memiliki peran vital dan strategis dalam pembangunan ekonomi nasional. UMKM adalah salah satu pelaku kunci dalam proses pembangunan nasional. UMKM berperan penting dalam pertumbuhan perekonomian negara dan penyerapan tenaga kerja untuk itu pemberdayaan UKM perlu dilakukan dengan serius (Narto et al., 2020) (Muljanto, 2020).

Pesatnya perkembangan teknologi, dunia digital dan internet tentu juga berimbas pada dunia pemasaran. Tren pemasaran di dunia beralih dari yang semula konvensional (offline) menjadi digital (online). Strategi digital marketing ini lebih prospektif karena memungkinkan para calon pelanggan potensial untuk memperoleh segala macam informasi mengenai produk dan bertransaksi melalui 
internet (Purwana et al., 2017). Selain itu pemasaran produk menggunakan digital marketing dan memanfaatkan media sosial untuk dapat menjangkau konsumennya secara langsung dan dapat menekan biaya promosi (Hardilawati, 2020).

Digital marketing merupakan pemasaran yang dilakukan dengan menggunakan akses internet, memanfaatkan media sosial dan perangkat digital lainnya. Digital Marketing dapat membantu membantu pelaku usaha contohnya adalah UMKM dalam mepromosikan dan memasarkan produk dan jasa mereka dan mampu memperluas pasar baru yang sebelumnya tertutup atau terbatas karena adanya keterbatasan waktu, jarak dan cara berkomunikasi (Prabowo, 2018). Media internet yang sekarang ini populer digunakan untuk pemasaran produk antara lain, Facebook, Youtube, Instagram, dan media sosial yang lain. Manfaat yang didapatkan dengan digital marketing selain bisa menjangkau pasar yang lebih luas dan mengefektifkan biaya pemasaran, juga membuat ruang dan waktu pemasaran yang tidak terbatas. Selain itu, digital marketing bersifat real time sehingga pengusaha dapat langsung memperhatikan minat dan feedback dari pasar yang dituju, serta dapat memutuskan strategi penyesuaian terkait konten iklan untuk hasil yang lebih baik dengan lebih cepat (Hendriadi et al., 2019).

Dusun Digelan 2 terletak di Desa Soropadan, Kecamatan Pringsurat, Kabupaten Temanggung. Dusun ini terdiri dari sekitar 500 jiwa penduduk yang rata-rata yang bermata pencaharian sebagai pekerja pabrik. Beberapa diantaranya juga mendirikan usaha mandiri diantaranya adalah industri Indah Jaya yang terkenal dengan produk makaroninya. Dalam produksi makaroni setiap bulan Industri Indah Jaya menghabiskan sekitar 2 Ton makaroni mentah.

Industri Indah Jaya menjual makaroni dengan rasa original dan pedas yang diberi nama Makaroni Bajak Laut. Penjualan industri Indah Jaya selama ini mengharuskan konsumen yang ingin memesan atau membeli produk untuk datang langsung ke lokasi atau memesan lewat WhatsApp untuk melihat produk yang akan dibeli. Solusi dari masalah yang dihadapi oleh industri Indah Jaya adalah membuat akun sosial media atau marketplace untuk memudahkan dalam memesan dan melihat detail produk serta harga produk yang akan dipesan atau dibeli. Akun sosial media dan marketplace ini juga mempermudah konsumen yang berada di luar daerah, agar konsumen tidak perlu repot untuk datang ke lokasi untuk membeli atau memesan produk yang ada pada industri Indah Jaya. Dengan adanya pelatihan tentang bagaimana memasarkan suatu produk lewat media sosial dan marketplace didapatkan juga ilmu tentang bagaimana kemasan dan ajakan yang menarik minat konsumen. Dengan adanya pelatihan ini pula, masyarakat dapat lebih mengenal kemajuan teknologi dan dapat menggunakannya dengan sebaik mungkin dalam kehidupan sehari-hari. Selain itu, dengan adanya akun sosial media atau marketplace dapat mengedukasi masyarakat untuk lebih mengenal teknologi dalam dunia pemasaran. Dan adanya kemasan yang menarik dapat meningkatkan minat konsumen.

\section{METODE}

Pelaksanaan kegiatan Pengabdian kepada Masyarakat (PKM) yang dilaksanakan menggunakan metode transfer ilmu pengetahuan kepada mitra melalui pelatihan dan pendampingan dilaksanakan selama 2 (dua) bulan dengan total durasi pelaksanaan 80 Jam. Pendampingan dan pelatihan dilakukan dimulai dengan memberikan pengetahuan dan pemahaman dasar-dasar pemanfaatan sosial media sebagai sarana pemasaran hingga sampai mitra mampu melakukan pemanfaatan secara berkelanjutan.

Metode penyelesaian masalah dalam program pengabdian masyarakat di UMKM Makaroni Bajak Laut dengan metode penyelesaian berupa pelatihan, pendampingan, dan monitoring evaluasi. Pelatihan berlangsung selama 30 jam, pendampingan berlansung selama $30 \mathrm{jam}$, dan monitoring evaluasi berlangsung selama 20 jam.

Tahap pelatihan terdiri dari beberapa kegiatan yaitu: (1) pelatihan pengenalan packaging dan branding merupakan pelatihan terkait pengemasan dan merk produk; (2) pelatihan dokumentasi produk merupakan pelatihan terkait cara pengambilan gambar untuk produk yang akan di pasarkan; (3) pelatihan media sosial merupakan Pelatihan terkait media sosial untuk sarana pemasaran sebuah produk, dan cara memposting dan memberi caption yang menarik; (4) pelatihan marketplace merupakan pelatihan terkait marketplace untuk sarana pemasaran sebuah produk, dan cara memposting dan memberi caption yang menarik; (5) pelatihan menerima pesanan dan mengirim barang merupakan pelatihan terkait bagaimana 
menerima pesanan serta metode pembayarannya, mengirim barang melalui jasa antar paket.

Tahap pendampingan dilakukan dalam semua kegiatan baik dari segi packaging dan branding, pembuatan akun media sosial dan marketplace, pengambilan dokumentasi produk, posting produk di media sosial dan marketplace, serta menerima pesanan dan mengirim barang. Bentuk pendampingan yang dilakukan adalah memberikan kesempatan kepada pemilik UMKM melakukan ujicoba dari hasil pelatihan untuk mendapatkan penilaian awal dari hasil pelatihan yang sudah dilaksanakan.

Pada tahap monitoring evaluasi tim PKM akan penilaian lanjutan dari pendampingan yaitu dengan menguji secara praktik pemilik UMKM dimulai dari pengambilan dokumentasi produk, posting produk di media sosial dan marketplace, menerima pesanan, dan terakhir adalah mengirimkan barang pesanan konsumen. Monitoring evaluasi perlu dilakukan untuk mengetahui kesiapan pemilik UMKM dalam memanfaatkan Digital Marketing setelah pelatihan yang dilakukan. Dari pelaksanaan tahap monitoring evaluasi diharapkan dapat memberikan data terkait kesiapan pemilik UMKM dalam menerapkan Digital Marketing.

\section{HASIL DAN PEMBAHASAN}

Program kerja yang dilakukan selama program Pengabdian Kepada Masyarakat terdiri dari perancangan packaging, rebranding, inovasi pada produk, selanjutnya marketing. Proses pemilihan prioritas permasalahan berdasar dari hasil wawancara bersama dengan mitra dan analisis terkait kemungkinan yang ada dan bisa dilaksanakan secara maksimal sesuai kebutuhan mitra.

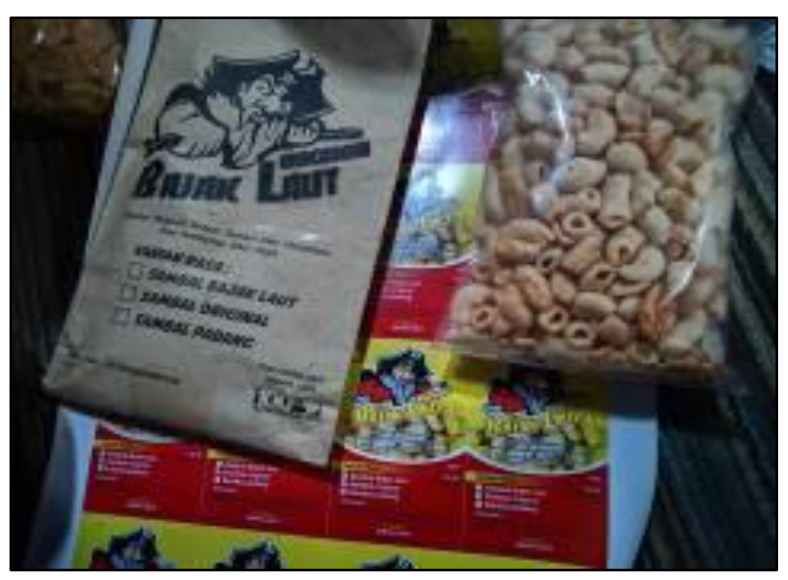

Gambar 2 Packaging Produk Lama

Packaging yang menarik tentu akan meningkatkan minat pembeli, dengan menganalisa kebutuhan dan kesesuaian produk dicapailah re-packaging dengan anggaran biaya yang lebih hemat dan juga lebih efisien. Tak luput juga branding yang ingin diperbaharui oleh mitra, selanjutnya diadakan pendampingan dalam re-branding produk yang tentunya lebih menarik dari yang sebelumnya.

Perbandingan packaging produk yang lama dengan packaging produk yang baru seperti yang terlihat pada Gambar 2 dan Gambar 3. Dari segi kemasan, package yang lama memerlukan 2 buah kemasan, yaitu dengan bahan kertas sebagai kemasan luar dan kemasan dalam menggunakan plastik tebal. Plastik tersebut memerlukan alat untuk press agar rapat dan ditempeli stiker brand produk. Sedangkan kemasan kertas masih perlu dicetak brand produk. Total biaya dari per satuan kemasan lama mencapai Rp 4000,-. Untuk kemasan baru hanya dengan satu kemasan yang sudah disertai zip lock, dan kemasan ini 2 in 1 yaitu bagian luarnya kertas, sedangkan dalamnya adalah alumunium. Total biaya per satuan kemasan baru beserta stiker hanya Rp 2000,-.
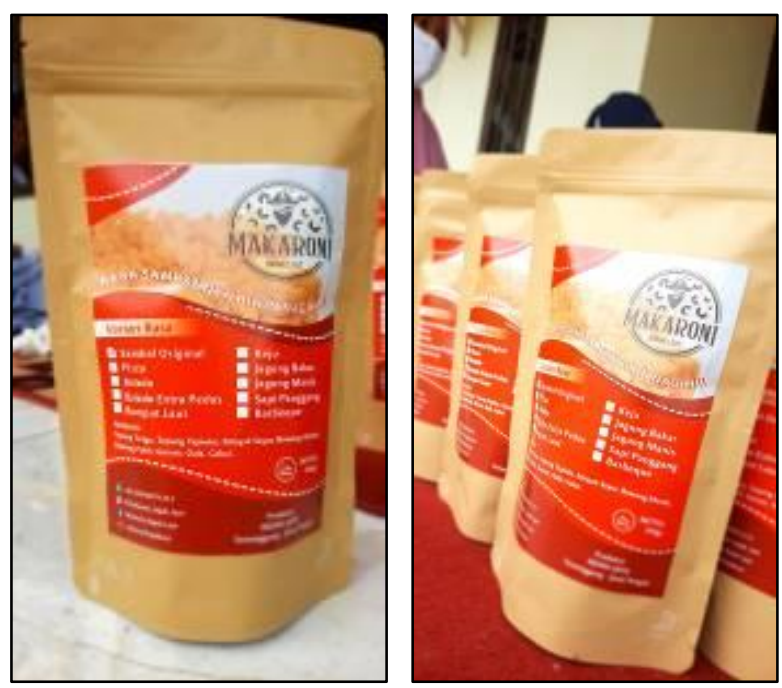

Gambar 3. Packaging Baru

Kegiatan selanjutnya adalah mitra didampingi dalam pelatihan dalam pengambilan gambar produk. Hal ini tentu sangat diperlukan mengingat dalam dunia digital marketing tentu sebuah gambar dari suatu produk adalah hal yang vital, gambar yang sesuai kenyataan produk akan menambah nilai tersendiri, seperti yang terlihat pada Gambar 3.

Setelah pengambilan gambar produk dilanjutkan dengan pelatihan tentang media sosial dan marketplace. Mitra diberi pengetahuan terkait media sosial dan marketplace yang tentu sangat diperlukan dalam digital marketing. 
Media sosial dan marketplace populer digunakan karena selain user friendly tentu mudah dalam penggunaannya. Selanjutnya mitra didampingi dalam pembuatan akun media sosial dan marketplace, selain itu juga bagaimana cara memposting suatu produk dengan gambar yang diambil dengan metode yang baik, serta caption yang menarik untuk diposting di akun media sosial dan marketplace. Media sosial dari UMKM Makaroni Bajak Laut seperti yang terlihat pada Gambar 3.

Selain menggunakan metode yang sudah dipakai oleh mitra dalam mengirimkan pesanan dari konsumen, juga diperkenalkan metode baru dalam proses kirim barang dan terima orderan. Karena jika tetap menggunakan metode lama seperti menggunakan WhatsApp tentu akan merepotkan mitra, juga ketertarikan pembeli jika terdapat metode yang lebih mudah tentu menggunakan metode baru tersebut.

Setelah pelatihan tahap selanjutnya adalah pendampingan. Pendampingan dilakukan dalam semua kegiatan baik dari segi pembuatan akun media sosial dan marketplace, postingan produk, packaging dan branding, serta menerima orderan dan mengirim barang.

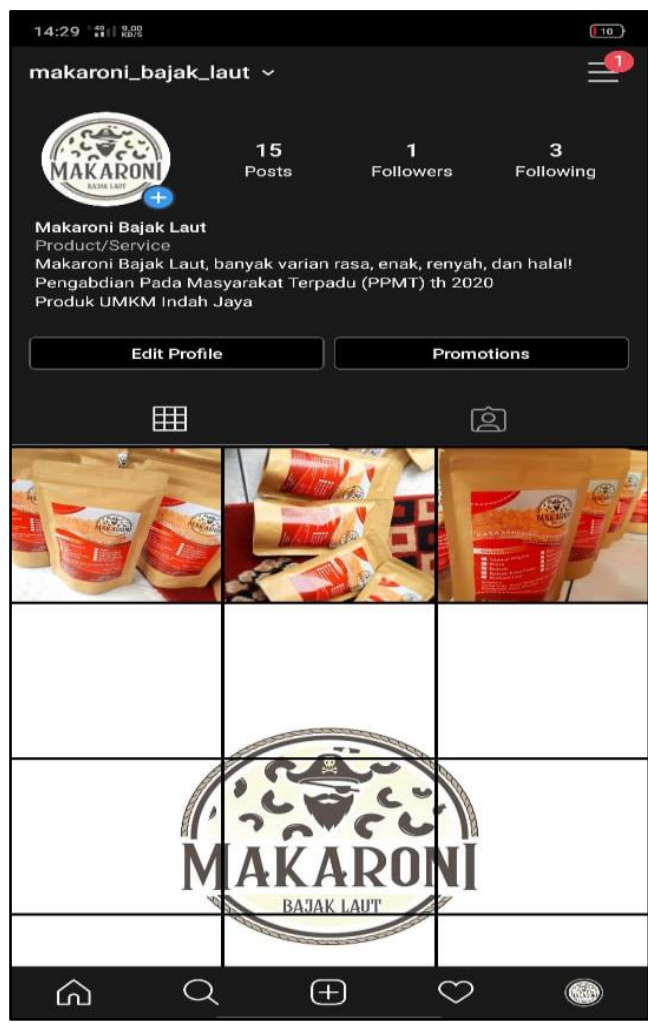

Gambar 4. Promosi Melalui Instagram

Berdasarkan dari pelaksanaan kegiatan pelatihan, pendampingan, dan monitoring evaluasi diperoleh informasi tentang hasil
Pengabdian Kepada Masyarakat di UMKM Makaroni Bajak Laut sebagai berikut:

1. UMKM Makaroni Bajak Laut memiliki packaging baru dengan biaya lebih hemat dan visualisasi yang lebih menarik.

2. UMKM Makaroni Bajak Laut memiliki akun di media sosial dan marketplace dari yang sebelumnya belum memiliki.

3. Pemilik dan karyawan UMKM Makaroni Bajak Laut memiliki peningkatan skill dalam pengambilan foto produk.

4. Pemilik dan karyawan UMKM Makaroni Bajak Laut mendapatkan skill baru tentang tata cara manajemen media social dan marketplace.

5. Pemilik dan karyawan UMKM Makaroni Bajak Laut mendapatkan skill baru tentang menerima order dan mengirimkan pesanan konsumen.

\section{KESIMPULAN}

Kegiatan Pengabdian Kepada Masyarakat pada UMKM Makaroni Bajak Laut telah telaksana 4 program kerja yaitu perancangan packaging, rebranding, inovasi pada produk, dan marketing. Pemanfaatan konsep pemasaran berbasis teknologi digital ini menjadi harapan bagi UMKM Makaroni Bajak Laut untuk mengembangkan strategi pemasaran mereka dengan memanfaatkan media sosial dan marketplace sebagai sarana digital marketing.

Hasil dari Pengabdian Kepada Masyarakat adalah UMKM Makaroni Bajak Laut memiliki sosial media dan marketplace sebagai alat untuk melakukan promosi produk dan pemilik UMKM Makaroni Bajak Laut memiliki pemahaman tentang Digital Marketing serta mampu mengelola sosial media dan marketplace yang dimiliki. Rekomendasi pada pengabdian masyarakat selanjutnya adalah memberikan pelatihan dan pendampingan kepada mitra untuk membuat konten digital marketing berupa video.

\section{UCAPAN TERIMAKASIH}

Tim Pengabdian Kepada Masyarakat mengucapkan terima kasih atas terselenggaranya pengabdian ini kepada LP3M Universitas Muhammadiyah Magelang dan mitra pengabdian UMKM Makaroni Bajak Laut Kabupaten Temanggung. Pengabdian Kepada Masyarakat terselenggara pada Program Pengabdian Pada Masyarakat Terpadu (PPMT) Batch 1 Tahun 2020. 


\section{DAFTAR PUSTAKA}

Amri, A. 2020. Dampak Covid-19 Terhadap UMKM di Indonesia. BRAND Jurnal Ilmiah Manajemen Pemasaran. Vol 2 (1). 123-131 pp.

Hendriadi, A. A., Padilah, T. N., \& others. 2019. Pelatihan Digital Marketing Usaha Mikro, Kecil dan Menengah (UMKM) di Kabupaten Karawang. J-Dinamika. Vol 4(2).

Hardilawati, L. W. 2020. Strategi Bertahan UMKM di Tengah Pandemi Covid-19. Jurnal Akuntansi dan Ekonomika. Vol 10(1). 89-98 pp.

Muljanto, M. A. 2020. Pencatatan dan Pembukuan Via Aplikasi Akuntansi UMKM di Sidoarjo. Jurnal Ilmiah Pangabdhi. Vol 6 (1), 40-43 pp.

Narto, N., HM, G. B., \& others. 2020. Penguatan Strategi Pemasaran Pudak di Tengah Pandemi Covid-19 untuk Meningkatkan Keunggulan Bersaing Usaha Mikro Kecil Menengah Kota Gresik. Jurnal INTECH Teknik Industri Universitas Serang Raya. Vol 6(1). 48-54 pp.

Prabowo, W. A. 2018. Pengaruh Digital
Marketing terhadap Organizational Performance dengan Intellectual Capital dan Perceived Quality sebagai Variabel Intervening pada Industri Hotel Bintang Tiga di Jawa Timur. Jurnal Manajemen Pemasaran. Vol 12 (2). 101-112 pp. https://doi.org/10.9744/pemasaran.12.2.1 01-112

Purwana, D., Rahmi, R., \& Aditya, S. 2017. Pemanfaatan Digital Marketing Bagi Usaha Mikro, Kecil, Dan Menengah (UMKM) di Kelurahan Malaka Sari, Duren Sawit. Jurnal Pemberdayaan Masyarakat Madani (JPMM). Vol 1 (1).

https://jdih.kemenkeu.go.id/fullText/2005/14TA HUN2005UU.htm

Wardani, T. I., \& Wijonarko. 2018. Pengaruh Model Pembelajaran Kooperatif Tipe Investigasi Kelompok Berbasis Lokakarya Terhadap Pemahaman Petunjuk Operasional Komputer Multimedia dan Kemampuan Mengoperasikan Komputer Multimedia Visual Basic. In Prosiding Seminar Nasional Geotik 2018: Literasi Digital untuk Pendidikan Aman Berkelanjutan (pp. 265271). Pendidikan Teknik Informatika dan Pendidikan Geografi Fakultas Keguruan dan Ilmu Pendidikan Universitas Muhammadiyah Surakarta. 
2 Jurnal Pangabdhi 